\title{
A Compact Multiband Multimode Antenna Employing Defected Ground Structure
}

\author{
Juin ACHARJEE ${ }^{1}$, Ram Lakhan KUMAR ${ }^{2}$, Kaushik MANDAL ${ }^{3}$, Sujit Kumar MANDAL ${ }^{4}$ \\ ${ }^{1}$ Dept. of Electronics \& Communication Eng., St. Thomas' College of Engineering \& Technology, Kolkata,700023, India \\ ${ }^{2}$ Dept. of Electronics \& Communication Engineering, NSHM Knowledge Campus, Durgapur, 713212, India \\ ${ }^{3}$ Inst. of Radio Physics and Electronics, University of Calcutta, Kolkata, 700009, India \\ ${ }^{4}$ Dept. of Electronics and Communication Engineering, NIT Durgapur, 713209, India \\ juin.ece@gmail.com
}

Submitted March 17, 2019 / Accepted October 3, 2019

\begin{abstract}
An analysis of shorting pin loaded compact triple-band antenna with triple-mode characteristics is carried out in this paper. The antenna structure is designed with a rectangular patch loaded with open edge slots to excite the fundamental $\mathrm{TM}_{10}$ mode at $2.51 \mathrm{GHz}$ and two modified inverted F-shaped defected ground structures (DGS) for the $T M_{20}$ and $T M_{30}$ modes at $5.26 \mathrm{GHz}$ and $8.18 \mathrm{GHz}$, respectively. A design formula for the fundamental resonant frequency of the basic structure is presented using multiple linear regression technique. The experimental results show good agreement with the simulated results
\end{abstract}

\section{Keywords}

Multiband, multimode, PIFA, DGS, cross polarization, ISM, WLAN, ITU

\section{Introduction}

In today's trending world of wireless communication, due to the massive use of wireless transceiver systems, there is a demand for the compact multiband antenna with large operating bandwidth and moderate gain. In the recent development of multiband microstrip patch antenna, the focus is mainly on popular frequency bands like Bluetooth (2.4-2.45 GHz), WLAN systems for IEEE 802.11a (5.15 to $5.35 \mathrm{GHz})$, and ITU $(8.02-8.4 \mathrm{GHz})$ bands [1]. To meet the requirement of small size wireless devices the demand of compact multiband antenna has been increased. Since planar inverted F antenna (PIFA) can operate in the lowest resonant mode with narrow bandwidth; as a result, it is suitable for designing a compact multiband patch antenna. The traditional design of PIFA consists of one radiating patch supported by a shorting wall and shorting post to excite a single resonant frequency with significantly reduced size of quarter wave length. Various techniques like the use of U-shaped slot [2], [3] on the PIFA radiator, combination of slotted patch and ground plane on the planar microstrip antenna [4] have been adopted to achieve multi-band performance. Small size PIFA for wireless communication [5] applications by loading capacitive plate between the radiator and ground plane and taking different slit at different position can be designed. Design of quadband PIFA by incorporating the combination of DGS and slot on the radiator is one of the reported techniques for antenna size reduction [6]. High gain integrated antenna design using stepped impedance PIFA along with power amplifier on the same ground plane is also reported technique for antenna miniaturization [7]. However, the major limitation of a microstrip patch antenna, resonating at its fundamental mode to radiate linearly polarized field in the intended reference plane is the radiation of cross-polarization (XP) in the orthogonal plane. The XP radiation is mainly due to the combined effect of orthogonal components of the dominant mode to the H-plane and spurious radiations from the improper feed. However, the E-plane $\mathrm{XP}$ radiation is always insignificant due to the non-existence of orthogonal fields to this plane as detailed in [8]. Still, some amount of XP radiation occurs in this plane due to the improper feed. Spurious radiation is higher in case of microstrip line feed due to the discontinuity at the transition of microstrip line and patch. Such discontinuity provides an equivalent shunt capacitance and its effect can be nullified by incorporating appropriate DGS. In this regards, differently shaped DGSs such as arc-shaped DGSs [9], asymmetric DGS [10], and dot-shaped DGS [11] have been conceived for XP reduction at a single frequency band. A different approach of multiband antenna design with improved co-pol to x-pol isolation using external RF switch and DGS is reported [12]. Instead of DGS, insertion of a pair of shorting walls underneath the non-radiating edge of the conventional shorted patch antenna is one of the reported techniques for designing wideband reduced XP antenna [13]. Thus the design of a multiband antenna with moderate XP level at every frequency band is a challenging task to the antenna designers.

In this paper, considering all the pros and cons of different PIFA structures, a shorting pin loaded triple-band antenna with triple-mode characteristics has been presented. Three modes are excited at three useful bands 
(namely ISM, WLAN, and ITU) by employing slotted patch and two inverted F-shaped DGSs. These DGSs also help to reduce the XP level by suppressing orthogonal components of the dominant mode. XP reduction along with excitation of a new resonant mode by using the same DGS structure has been adopted successfully for the first time. The physical insight of XP reduction due to DGS incorporation has been explained and analyzed thoroughly. Maximum XP reductions of $17 \mathrm{~dB}$ and $7 \mathrm{~dB}$ have been observed in the H-plane for the ISM band and WLAN band, respectively. The XP reduction performance in the diagonal planes of radiation is also obtained in the satisfactory range. All the simulations are carried out using the FEM-based Ansys HFSS EM simulator.

The rest of the paper is organized as follows. Antenna design concepts and the structure have been described in Sec. 2. Electric field distributions are analyzed minutely in Sec. 3 for the mode identification and to understand the physical insight of the XP suppression. Section 4 validates the simulated results and finally, concluding remarks are presented in Sec. 5.

\section{Antenna Design and Configuration}

The basic structure of the antenna consisting of a rectangular patch and a metallic post (shorting pin) of diameter $0.6 \mathrm{~mm}$ in between the patch and ground is taken as the reference antenna. Figure 1 shows the detailed diagram of the proposed antenna with overall dimension $24 \mathrm{~mm} \times$ $3 \mathrm{~mm} \times 1.6 \mathrm{~mm}$. FR4 substrate with dielectric constant $\varepsilon_{\mathrm{r}}=4.4$, height $h=1.6 \mathrm{~mm}$, and loss tangent of 0.02 is used for this design. To calculate the fundamental resonating frequency $f_{\mathrm{r}}$ of the microstrip line feed antenna structure, a design formula is derived as

$$
f_{\mathrm{r}}=5.96+0.06 w+0.29 l
$$

where width $w$ and length $l$ of the radiating patch are in $\mathrm{mm}$ and resonating frequency $f_{\mathrm{r}}$ is in $\mathrm{GHz}$.

Equation (1) is derived by using multiple linear regression technique [14] on the simulated data sample of reflection coefficients. The stepwise development of the proposed structure, starting from the basic design is shown in Fig. 2. The reference structure has been developed by applying (1) with the resonating frequency $8.13 \mathrm{GHz}$.

A staircase shaped slot is etched on the radiating patch of the reference antenna to excite a new resonance. This design is referred as Antenna-1 which resonates at $2.51 \mathrm{GHz}$ with frequency band $2.45-2.58 \mathrm{GHz}$. The primary resonance of the reference structure is disturbed due to insertion of this slot. For satisfying the multiband operation there is a demand for the generation of new resonance. An inverted F-shaped slot (DGS 1) is etched on the ground plane of length $0.38 \lambda_{0}$, where $\lambda_{0}$ is the free space wavelength corresponding to the center frequency to excite one more resonant condition at $5.26 \mathrm{GHz}$. The corresponding structure is referred as Antenna 2 which operates in the dual frequency bands. Insertion of this DGS 1 does not

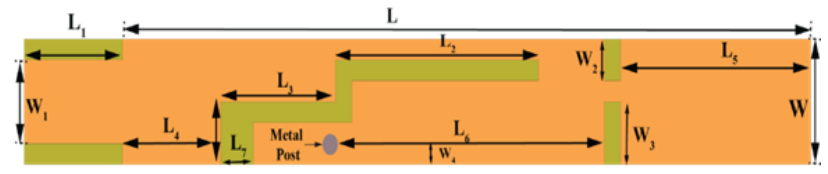

(a)

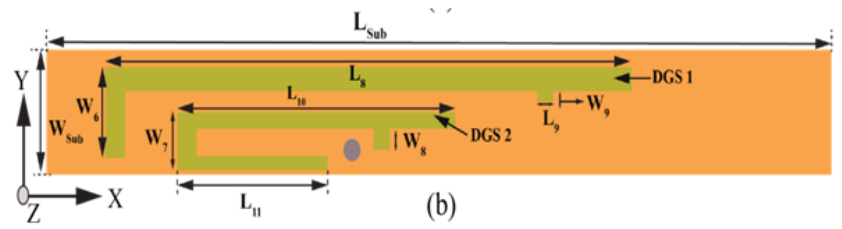

Fig. 1. Detailed diagram of the proposed multiband antenna: (a) top view, (b) bottom view.

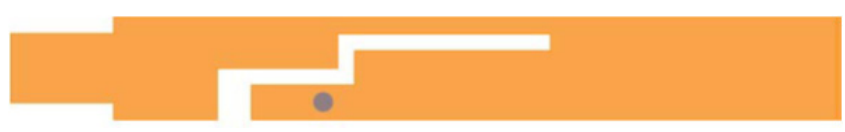

(a)

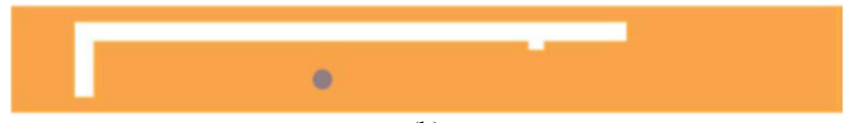

(b)

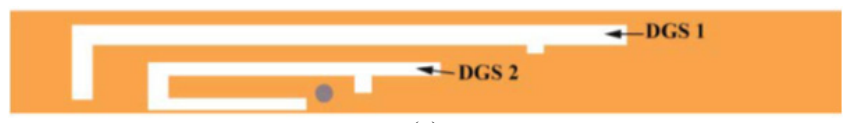

(c)

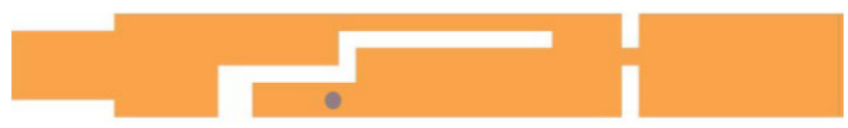

(d)

Fig. 2. Stepwise improvement of the proposed multiband antenna: (a) Antenna 1 (front view), (b) Antenna 2 (back view), (c) Proposed structure (back view), (d) Proposed structure (front view).

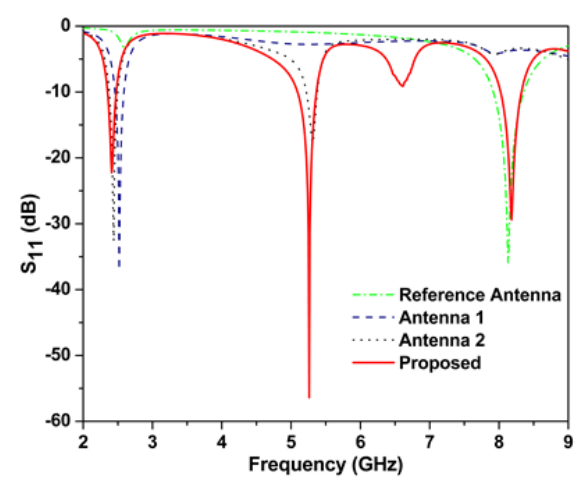

Fig. 3. Stepwise improvement of the simulated reflection coefficient of the proposed multiband antenna.

recover the extinct resonating frequency of the reference antenna; therefore one more relatively smaller modified inverted F-shaped slot (DGS 2) of length $0.34 \lambda_{0}$ is etched on the ground plane to retrieve the resonating frequency of the reference antenna. Dimensions and positions of all inserted slots are optimized to reduce XP level as well as to excite a new resonating mode. After the insertion of DGS 2, the antenna resonates at a new frequency $6.6 \mathrm{GHz}$ along with the earlier resonance of the reference antenna at $8.18 \mathrm{GHz}$. 


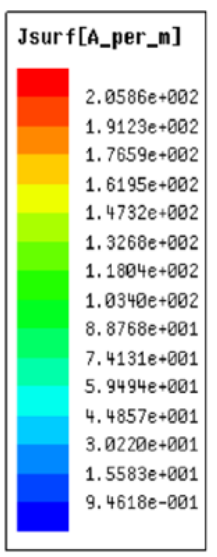

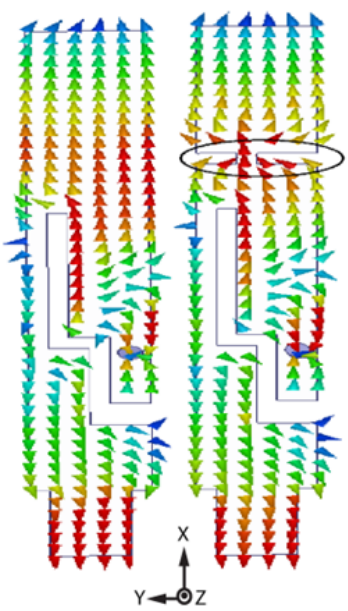

(a)

(b)

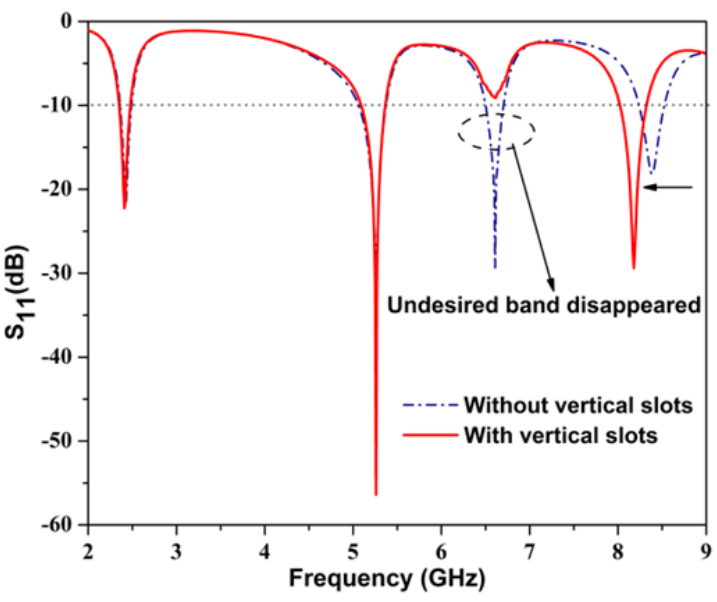

(c)

Fig. 4. Simulated current distribution at $6.6 \mathrm{GHz}$ : (a) without slot, (b) with a slot at the radiator, (c) effect of slots on reflection coefficient.

Finally, a pair of vertical open edge slots is etched at the optimized position on the patch to suppress the unintentionally excited resonant condition at $6.6 \mathrm{GHz}$. The simulated reflection coefficient for different antenna structures is summarized in Fig. 3. The surface current distributions on the patch with and without slots at the newly generated undesired resonance frequency $6.6 \mathrm{GHz}$ are shown in Fig. 4(a) and Fig. 4(b), respectively. It shows that more current is concentrated around the extreme right of the radiating patch. Therefore, to change the current distribution of that region a pair of vertical slots is etched and the corresponding effects on the reflection coefficient are shown in Fig. 4(c). These slots not only obliterate the unwanted resonance at $6.6 \mathrm{GHz}$ but also adjust the proper positioning of the third band for ITU application.

Optimized dimensions of the proposed PIFA structure in Fig. 1 are as follows: $W_{\mathrm{SUB}}=3 \mathrm{~mm}, L_{\mathrm{SUB}}=24 \mathrm{~mm}$ $L=21 \mathrm{~mm}, L_{1}=L_{4}=3 \mathrm{~mm}, L_{2}=62 \mathrm{~mm}, L_{3}=3.5 \mathrm{~mm}$, $L_{5}=5.8 \mathrm{~mm}, L_{6}=8.1 \mathrm{~mm}, L_{7}=1 \mathrm{~mm}, L_{8}=16.1 \mathrm{~mm}$, $L_{9}=0.5 \mathrm{~mm}, L_{10}=8.5 \mathrm{~mm}, L_{11}=4.6 \mathrm{~mm}, W_{1}=2 \mathrm{~mm}$, $W_{2}=1 \mathrm{~mm}, W_{3}=1.5 \mathrm{~mm}, W_{4}=0.5 \mathrm{~mm}, W_{5}=1.5 \mathrm{~mm}$, $W_{6}=2.06 \mathrm{~mm}, \quad W_{7}=1.4 \mathrm{~mm}, \quad W_{8}=0.5 \mathrm{~mm}, \quad$ and $W_{9}=0.25 \mathrm{~mm}$.

\section{Nature of Field Distribution and XP Radiation}

The proposed structure operates in the fundamental mode $\mathrm{TM}_{10}$. With the insertion of slots on the radiator and in the ground plane some other modes are also excited. Resonating frequency of the corresponding modes can be calculated using (2)

$$
f_{\mathrm{r}}(m, n)=\frac{c}{2 \sqrt{\varepsilon_{\text {eff }}}}\left[\left(\frac{m}{L+\Delta L}\right)^{2}+\left(\frac{n}{W+\Delta W}\right)^{2}\right]^{1 / 2}
$$

where $f_{\mathrm{r}}(m, n)$ is the resonant frequency of the excited modes in $\mathrm{GHz}, c$ is the velocity of light, $\varepsilon_{\mathrm{eff}}$ is the effective dielectric constant, and $m, n$ are the order of modes.

\begin{tabular}{|c|c|c|c|}
\hline \multirow{2}{*}{$\begin{array}{c}\text { Resonating } \\
\text { modes }\end{array}$} & \multicolumn{3}{|c|}{ Resonance frequency $(\mathrm{GHz})$} \\
\cline { 2 - 4 } & Calculated & Simulated & Measured \\
\hline $\mathrm{TM}_{10}$ & 2.8 & 2.51 & 2.51 \\
\hline $\mathrm{TM}_{20}$ & 5.6 & 5.26 & 5.26 \\
\hline $\mathrm{TM}_{30}$ & 8.4 & 8.18 & 8.17 \\
\hline
\end{tabular}

Tab. 1. Comparison of resonance frequencies for the excited modes of the proposed antenna.

Identification of those modes have been done by the following [15] and compared in Tab. 1.

The investigation on radiating fields for the excited modes can be visualized by simulated electric field distributions on the antenna as shown in Fig. 5. Therefore, the excited fundamental and higher order modes of the proposed structure are $\mathrm{TM}_{10}, \mathrm{TM}_{20}$ and $\mathrm{TM}_{30}$.

To visualize the effect of DGS on XP reduction at different resonating frequencies, the comparisons of electric field distributions for various conditions are shown in Fig. 6 and Fig. 7. It shows that low XP level at $\mathrm{TM}_{10}$ mode is obtained whereas the acceptable level is obtained for the $\mathrm{TM}_{20}$ mode. For the optimized length and position of the DGSs, the slot impedance decreases according to the (3) and (4) as described in [16].

$$
\begin{gathered}
n=\sqrt{\frac{Z_{0}^{\text {Microstrip }}}{Z_{0}^{\text {Slot }}},} \\
Z_{0}^{\text {Slot }}=\frac{\eta^{2}}{4 Z_{\mathrm{d}}}
\end{gathered}
$$

where $Z_{\mathrm{d}}$ is the input impedance of the dipole resonator complementary to the slot, $\eta$ is the intrinsic impedance and $n$ is the coupling between microstrip line and embedded slot on the ground. In the structure, the dipole resonator is complementary to the ground slot. For the resonating length of the dipole resonator the impedance $Z_{\mathrm{d}}$ increases which in turn reduces the impedance $Z_{0}^{\text {Slot }}$ of the ground slot as per (4). Due to this reduction of the slot impedance 


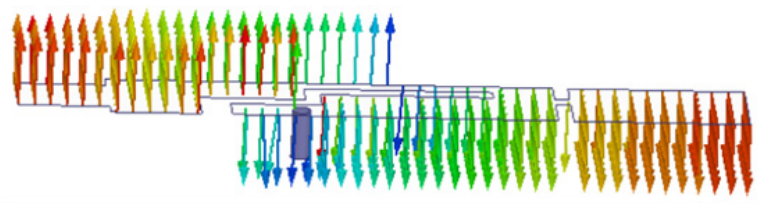

(a)

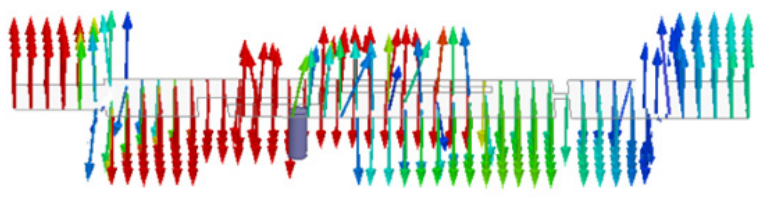

(b)

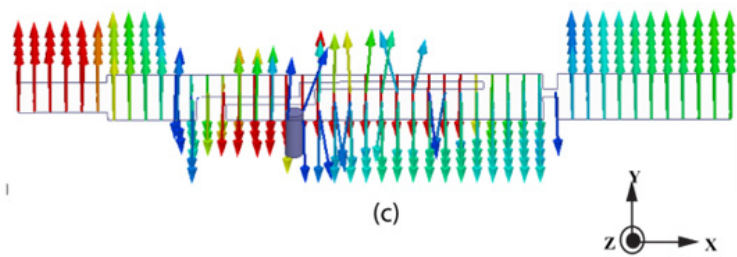

Fig. 5. Simulated electric field distributions at various modes: (a) $\mathrm{TM}_{10}$, (b) $\mathrm{TM}_{20}$, and (c) $\mathrm{TM}_{30}$

the coupling $n$ between microstripline feed upper patch and ground slot increases following (3). Therefore, more energy is stored in the ground plane and the generated orthogonal fields are trapped into the DGS, which results in a reduction of XP level at the corresponding frequency band. When the length of the dipole resonator decreases, the $\theta$ components [17] of the electric field intensity also de- creases which in turn reduces the intrinsic impedance $Z_{\mathrm{d}}$ of the dipole. So, reduction of the dipole resonator's impedance increases the impedance of the ground slot. Therefore, the coupling reduces between the patch and ground plane. Hence, less number of orthogonal fields are trapped within the ground slot. The order of orthogonal field suppression and its effect on the XP, for different length of DGSs, are summarized in Fig. 6 and Fig. 7. For the fundamental mode, it shows a significant amount of XP reduction of about $9-17 \mathrm{~dB}$ compared to the shorting pin loaded reference antenna at boresight in both the principal radiation planes. It has been observed that XP reduction is maximum $(17 \mathrm{~dB})$ in the H-plane around $\pm 60^{\circ}$. Moderate level of XP reduction $(5-7 \mathrm{~dB})$ at boresight in both the principal planes is realized for the second higher order mode. It is also found that the XP performance of the proposed structure in the diagonal radiation planes $\left(\varphi=45^{\circ}\right.$, and $\left.135^{\circ}\right)$ is also satisfactory for the fundamental mode $(2.51 \mathrm{GHz})$ as shown in Fig. 8.

The reduction of XP level is not very high for all the resonant conditions because there should be a trade-off between the resonant length and the position of the slot for perturbation of orthogonal fields. Moreover, the XP radiation due to surface wave is also significant at the higher frequencies as the substrate becomes electrically thick $\left(h \lambda_{0}\right)$. Hence, there is no noteworthy improvement in XP performance at $8.18 \mathrm{GHz}$ and not presented for brevity. So, the position of DGS is optimized to achieve a significant

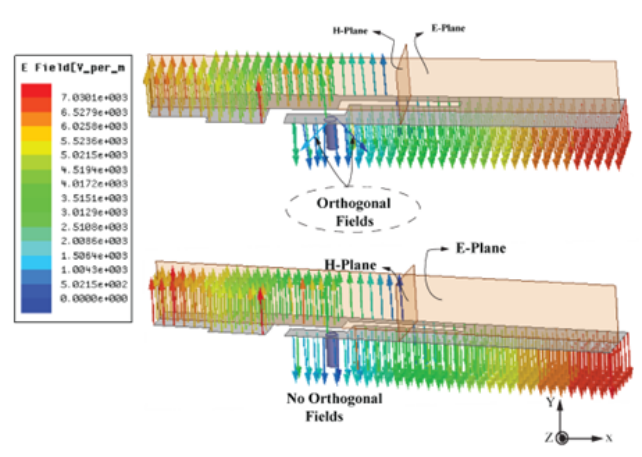

(a)

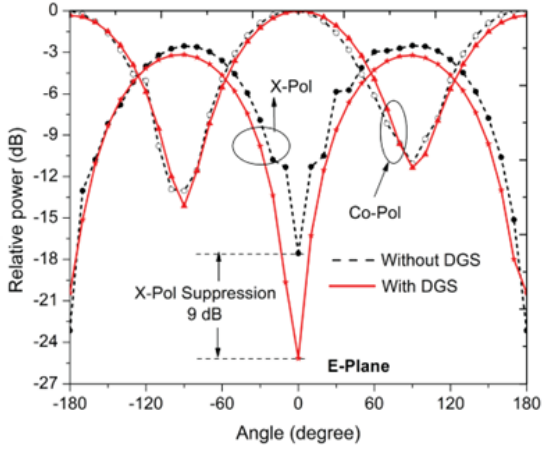

(b)

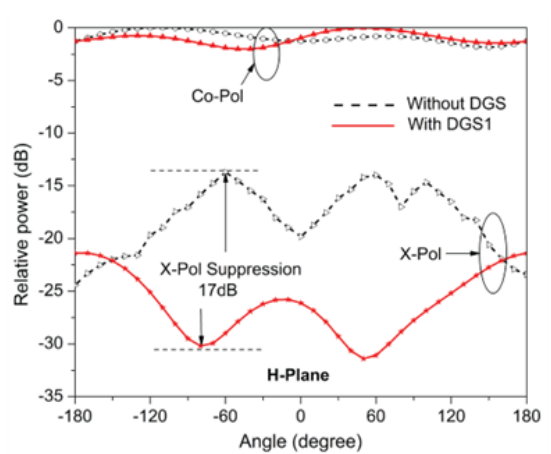

(c)

Fig. 6. Effect of insertion of DGS 1 at $2.51 \mathrm{GHz}$ : (a) suppression of orthogonal electric field, (b) XP reduction at E-plane, (c) XP reduction at H-plane.

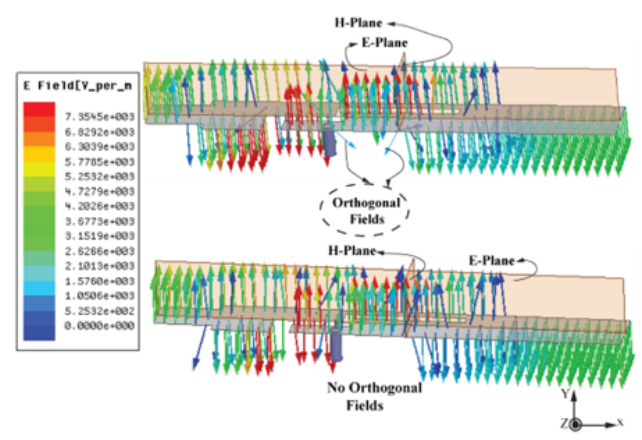

(a)

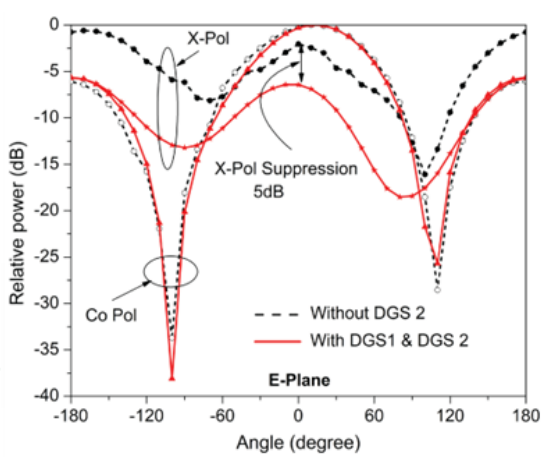

(b)

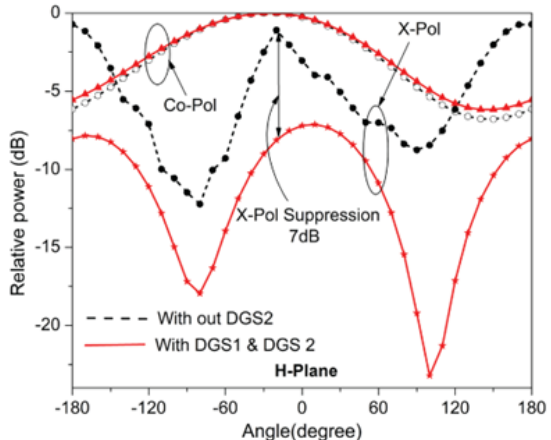

(c)

Fig. 7. Effect of insertion of DGS 1 at $5.26 \mathrm{GHz}$ : (a) suppression of orthogonal electric field, (b) XP reduction at E-plane, (c) XP reduction at H-plane. 


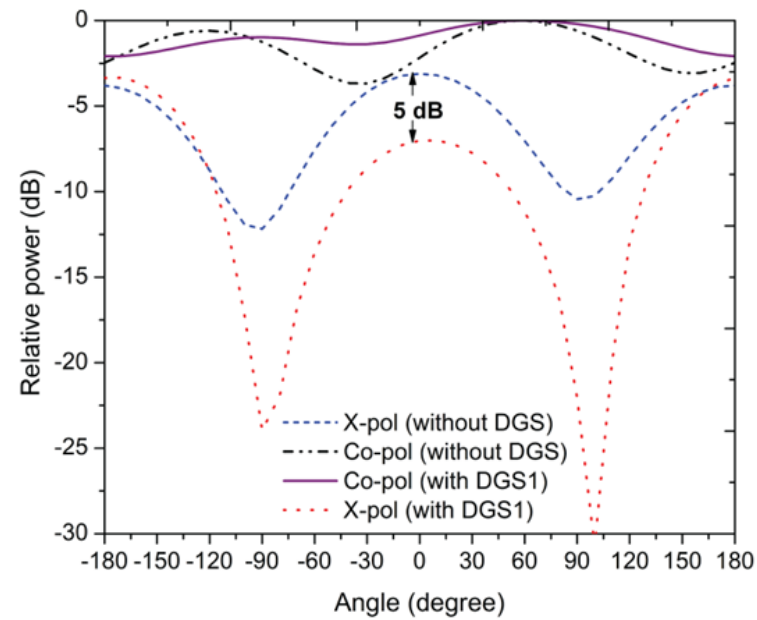

(a)

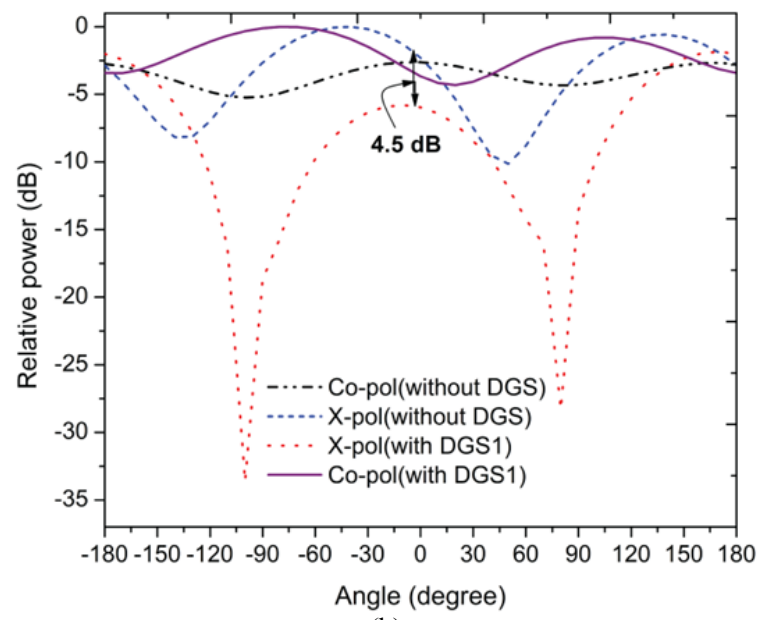

(b)

Fig. 8. Simulated radiation patterns in diagonal planes at $2.51 \mathrm{GHz}$ (a) $\varphi=45^{\circ}$, and (b) $\varphi=135^{\circ}$.

amount of XP reduction in both the principal and diagonal planes by suppressing the orthogonal fields to the H-plane as well as by minimizing the spurious radiations due to improper feed.

\section{Result and Discussion}

A prototype of the proposed structure was fabricated to validate the simulated results. A good agreement between the simulated and measured reflection coefficients is observed, as shown in Fig. 9. Photo of the fabricated prototype is also shown in the inset of Fig. 9. The proposed antenna operates over the frequency bands $2.35-2.47 \mathrm{GHz}$, 5.08-5.36 GHz, and $8.01-8.31 \mathrm{GHz}$ which mainly covers $2.51 \mathrm{GHz}$ ISM band, $5.26 \mathrm{GHz}$ WLAN band, and $8.18 \mathrm{GHz}$ ITU application bands respectively. Radiation mechanism of the proposed PIFA antenna can be understood from the surface current distribution at different frequencies, as shown in Fig. 10. These current distributions on the top layer and ground plane justify the conversion of the single band to the dual-band and finally to the triple band property. Figure 10(a) shows the current distribution at the resonating frequency $2.51 \mathrm{GHz}$. At this

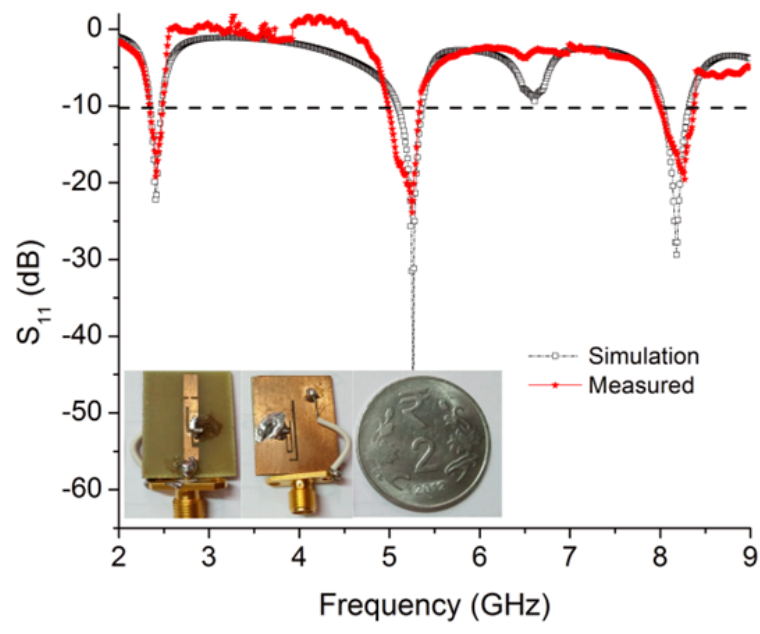

Fig. 9. Comparison between simulated and measured reflection coefficient.

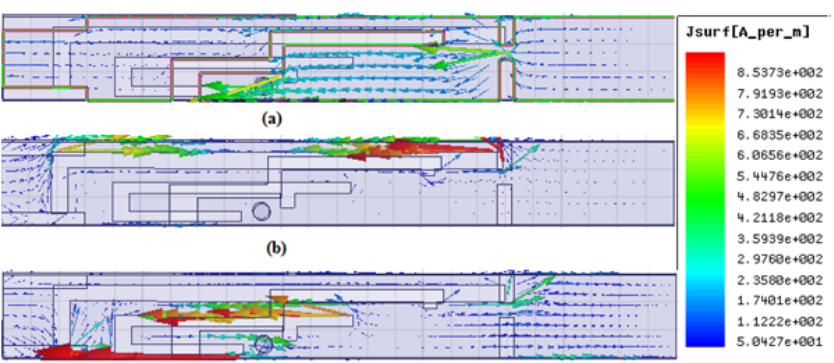

(c)

Fig. 10. Simulated current distribution at three different resonating frequencies: (a) $2.51 \mathrm{GHz}$, (b) $5.26 \mathrm{GHz}$, and (c) $8.18 \mathrm{GHz}$.

frequency, more current is concentrated around the staircase slot on the radiator. Figure 10(b) and 10(c) ensure that the DGS 1 and DGS 2 are responsible for the resonances at $5.26 \mathrm{GHz}$ and $8.18 \mathrm{GHz}$, respectively.

The simulated and measured co-pol and X-pol radiation patterns at three different resonating frequencies in both the principal planes E-plane (XZ-plane) and H-plane (YZ-plane) are shown in Fig. 11. Gain measurement at three different resonating frequencies is also a very important aspect of an antenna design. During gain measurement three antennas, the antenna under test (AUT), reference antenna with a high degree of dimensional stability and polarization purity, and a "don't care" antenna (X) are used. Initially, the reference antenna as a receiver and the ' $\mathrm{X}$ ' antenna as a transmitter are connected to the network analyzer with proper polarization and direction of maximum radiation intensity. This connection setup with flat $0 \mathrm{~dB}$ response in the network analyzer over the selected frequency range helps to normalize the gain of the reference antenna. Secondly, the reference antenna is replaced by the AUT and the $\mathrm{S}_{21}$ response is observed, and noted as $G_{\text {Relative }}$. Now, the gain of the AUT $G_{\text {AUT }}$ is determined by (5) at every frequency point

$$
G_{\mathrm{AUT}}=G_{\mathrm{REF}}+G_{\mathrm{RELATIVE}}
$$

where $G_{\mathrm{REF}}$ is the gain of the reference antenna. The Wheeler cap [18] method is used to determine the radiation 

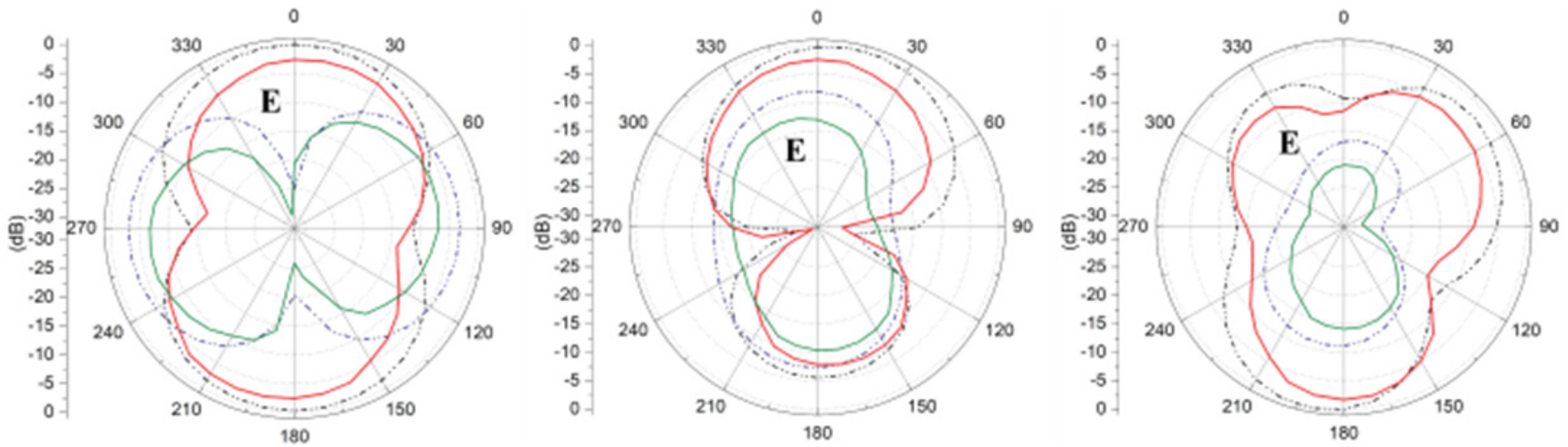

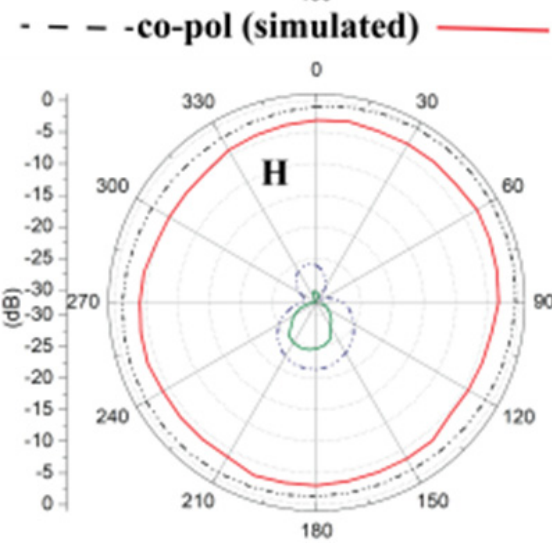

(a)

co-pol (measured) - - - - x-pol (simulated)

x-pol (measured)

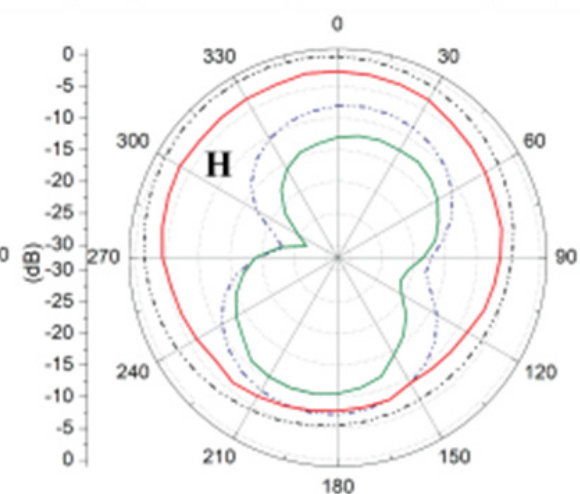

(b)

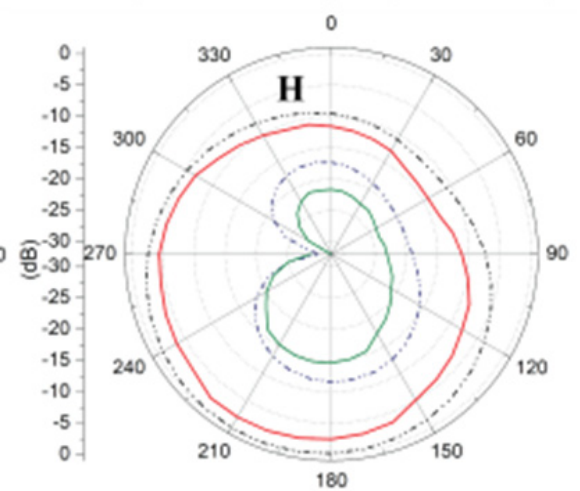

(c)

Fig. 11. Simulated and measured radiation patterns at three different resonating frequencies: (a) $2.51 \mathrm{GHz}$, (b) $5.26 \mathrm{GHz}$, and (c) $8.18 \mathrm{GHz}$.

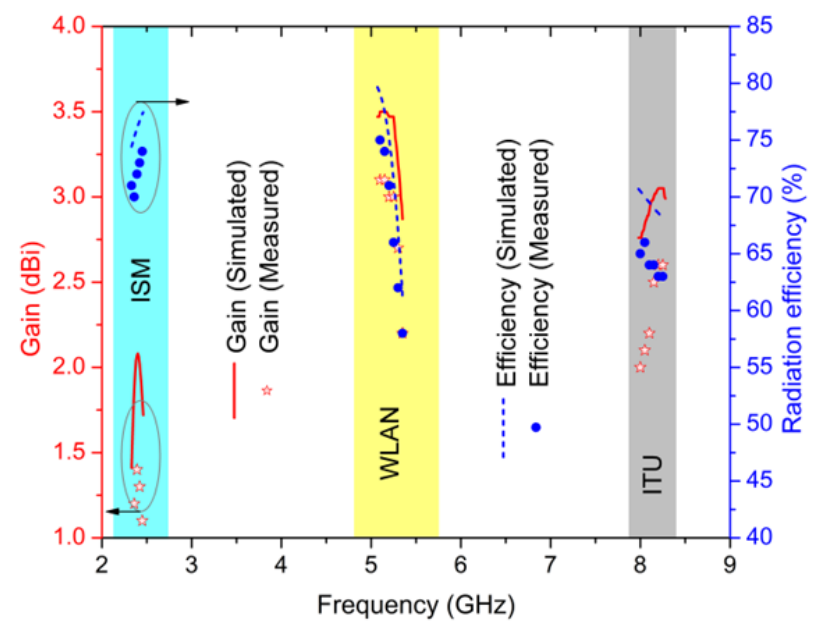

Fig. 12. Simulated and measured gain variation and radiation efficiency variation at three different application bands.

efficiency of the AUT. Figure 12 shows the simulated and measured gain variation as well as radiation efficiency at three different application bands. It shows the gain variation of $1.2-3.18 \mathrm{dBi}$ and efficiency variation of $57-74 \%$, which is acceptable for the practical applications. The proposed structure of the multiband multimode antenna is nearly similar with the PIFA structure excepting the shorting wall at the opposite side of the microstripline feed. Therefore, to enlighten the advantages of the proposed structure over the other reported PIFA structures, a comparative study is carried out and summarized in Tab. 2. It is found that the overall size of the proposed structure is minimum compared to others. Further, there are no other multiband PIFA works [4-6] that exhibit XP reduction property. XP reduction performance of this antenna in comparison to the related works [9-11] is also above the satisfactory level.

\section{Conclusion}

A simple structured triple-band antenna with a proposed design formula for the fundamental resonant frequency is presented and analyzed. Shape, size, and positions of the DGSs are crucial to excite higher-order modes and to suppress orthogonal fields, which are the main contributors towards XP. Radiated electric fields have been investigated minutely to identify the modes as well as to confirm the suppression of orthogonal fields. The proposed antenna operates at $2.51 \mathrm{GHz}$ ISM, $5.26 \mathrm{GHz}$ WLAN, and $8.18 \mathrm{GHz}$ ITU bands with reasonable bandwidth. Moderate gain with desirable radiation properties and the good agreement between simulated and measured results ensure the acceptance of this antenna for the wireless communication systems.

\section{Acknowledgment}

This work is financially supported by the Ministry of Electronics and Information Technology (MeitY), Govt. of India under Visvesvaraya Young Faculty Fellowship Visvesvaraya Ph.D. scheme (Grant No. Ph.D.-MLA-4(29)/ 2015-16). 


\begin{tabular}{|c|c|c|c|c|c|c|}
\hline Ref. no. & $\begin{array}{c}\text { Operating frequency } \\
(\mathrm{GHz})\end{array}$ & Size of antenna $\left(\mathrm{mm}^{2}\right)$ & Gain $(\mathrm{dBi})$ & \multicolumn{2}{|c|}{$\mathrm{XP}$ suppression } & $\begin{array}{c}\text { Maximum radiation } \\
\text { efficiency }\end{array}$ \\
\hline [2] & $2.4,5.2$ & $0.12 \lambda_{0} \times 0.1 \lambda_{0}$ & NM & \multicolumn{2}{|c|}{ NM } & $\mathrm{NM}$ \\
\hline [3] & 2.4, 5.1(approx.) & $0.12 \lambda_{0} \times 0.1 \lambda_{0}$ & NM & \multicolumn{2}{|c|}{ NM } & $\mathrm{NM}$ \\
\hline [4] & $2.5,3.5,5.5$ & $0.08 \lambda_{0} \times 0.208 \lambda_{0}$ & $2-9.1$ & \multicolumn{2}{|c|}{ NM } & $90 \%$ \\
\hline [5] & $0.95,1.8,2.45$, and 5.2 & $0.32 \lambda_{0} \times 0.19 \lambda_{0}$ & NM & \multicolumn{2}{|c|}{ NM } & NM \\
\hline [6] & $3.5,5.2$, and 7.5 & $0.3 \lambda_{0} \times 0.03 \lambda_{0}$ & 3-5.6 (approx.) & \multicolumn{2}{|c|}{ NM } & NM \\
\hline [9] & 5.93 & $1.0 \lambda_{0} \times 1.0 \lambda_{0}$ & NM & \multicolumn{2}{|c|}{$12 \mathrm{~dB}$} & NM \\
\hline [10] & 10 & $2.0 \lambda_{0} \times 2.0 \lambda_{0}$ & 2.4 & \multicolumn{2}{|c|}{$15 \mathrm{~dB}$} & NM \\
\hline [11] & 3.6 & $0.7 \lambda_{0} \times 0.7 \lambda_{0}$ & 5(approx.) & \multicolumn{2}{|c|}{$(5-8) \mathrm{dB}$} & NM \\
\hline [12] & $2.9,6$ & $0.44 \lambda_{0} \times 0.52 \lambda_{0}$ & NM & \multicolumn{2}{|c|}{$>12 \mathrm{~dB}\left(\mathrm{TM}_{10}\right) \& 5 \mathrm{~dB}\left(\mathrm{TM}_{20}\right)$} & $53 \% \& 64 \%$ \\
\hline [13] & 3.85 to 5.01 & $1.30 \lambda_{0} \times 0.76 \lambda_{0}$ & 8 & \multicolumn{2}{|c|}{$19.2 \mathrm{~dB}$} & Around $80 \%$ \\
\hline \multirow[b]{2}{*}{ Proposed } & \multirow[b]{2}{*}{$2.51,5.26$, and 8.18} & \multirow[b]{2}{*}{$0.2 \lambda_{0} \times 0.02 \lambda_{0}$} & \multirow[b]{2}{*}{$1.2-3.18$} & $2.51 \mathrm{GHz}$ & $5.26 \mathrm{GHz}$ & \multirow[b]{2}{*}{$74 \%$} \\
\hline & & & & $\begin{array}{c}9 \mathrm{~dB} \text { (E-plane) } \\
17 \mathrm{~dB} \text { (H-plane) }\end{array}$ & $\begin{array}{l}5 \mathrm{~dB} \text { (E-plane) } \\
7 \mathrm{~dB} \text { (H-plane) }\end{array}$ & \\
\hline
\end{tabular}

Tab. 2. Performance comparison with the related works.

\section{References}

[1] KUMAR. G., RAY, K. P. Broadband Microstrip Antennas. Artech House, 2003. ISBN: 978-1580532440

[2] SALONEN, P., KESKILAMMI, M., KIVIKOSKI, M. Single-feed dual-band planar inverted-F antenna with U-shaped slot. IEEE Transactions on Antennas and Propagation, 2000, vol. 48, no. 8, p. $1262-1264$. DOI: $10.1109 / 8.884498$

[3] ROW, J. S. Experimental studies of the dual-band planar invertedF antenna with a U-shaped slot. Microwave and Optical Technology Letters, 2003, vol. 37, p. 359-361. DOI: 10.1002/mop. 10917

[4] KUNWAR, A., GAUTAM, A. K., RAMBABU, K. Design of a compact U-shaped slot triple band antenna for WLAN/WiMAX applications. AEU - International Journal of Electronics and Communications, 2017, vol. 71, p. 82-88. DOI: 10.1016/j.aeue.2016.10.013

[5] NAShaAT, D. M., ElSADEK, H. A., GHALI, H. Single feed compact quad-band PIFA antenna for wireless communication applications. IEEE Transactions on Antennas and Propagation, 2005, vol. 53, no. 8, p. 2631-2335. DOI: 10.1109/TAP.2005.851872

[6] OJAROUDI, N., OJAROUDI, H., GHADIMI, N. Quad-band planar inverted-F antenna (PIFA) for wireless communication systems. Progress In Electromagnetics Research, 2014, vol. 45, p. 51-56. DOI: 10.2528/PIERL14012403

[7] GUNDUMALla, A., AGRAWAL, S., PARIHAR, M. S. Miniaturized active stepped impedance planar inverted-F antenna using common ground. AEU - International Journal of Electronics and Communications, 2017, vol. 83, p. 233-239. DOI: 10.1016/j.aeue.2017.08.041

[8] GARG, R., BHARTIA, P., BAHL, I., ITTIPIBOON, A. Microstrip Antenna Design Handbook. Norwood (MA, USA): Artech House, 2001. ISBN: 978-0890065136

[9] GUHA, D., KUMAR, C., PAL, S. Improved cross-polarization characteristics of circular microstrip antenna employing arcshaped defected ground structure (DGS). IEEE Antennas and Wireless Propagation Letters, 2009, vol. 8, p. 1367-1369. DOI: 10.1109/LAWP.2009.2039462

[10] KUMAR, C., GUHA, D. Asymmetric geometry of defected ground structure for rectangular microstrip: A new approach to reduce its cross-polarized fields. IEEE Transactions on Antennas and Propagation, 2016, vol. 64, no. 6, p. 2503-2506. DOI: 10.1109/TAP.2016.2537360

[11] GUHA, D., BISWAS, M., ANTAR, Y. M. M. Microstrip patch antenna with defected ground structure for cross polarization sup- pression. IEEE Antennas and Wireless Propagation Letters, 2005, vol. 4, no. 1, p. 455-458. DOI: 10.1109/LAWP.2005.860211

[12] KUMAR, J., BASU, B., TALUKDAR, F. A., et al. Multimodeinspired low cross-polarization multiband antenna fabricated using graphene-based conductive ink. IEEE Antennas and Wireless Propagation Letters, 2018, vol. 17, no. 10, p. 1861-1865. DOI: 10.1109/LAWP.2018.2868477

[13] LIU, N. W., ZHU, L., FU, G., et al. A low profile shorted-patch antenna with enhanced bandwidth and reduced H-plane crosspolarization. IEEE Transactions on Antennas and Propagation, 2018, vol. 66, no. 10, p. 5602-5607. DOI: 10.1109/TAP.2018.2855730

[14] CHATTERJEE, S., HADI, A. S. Regression Analysis by Example. $4^{\text {th }}$ ed. New Jersey: John Wiley \& Sons, 2006. DOI: $10.1002 / 0470055464$

[15] CHATTOPADHYAY, S., BISWAS, M., SIDDIQUI, J. Y., et al. On the resonance of rectangular microstrip patches with variable air gap and varying aspect ratio: Improved formulations and experiments. Microwave and Optical Technology Letters, 2009, vol. 51, no. 1, p. 169-173. DOI: 10.1002/mop. 24025

[16] GHOSH, A., GHOSH, D., CHATTOPADHYAY, S., et al. Rectangular microstrip antenna on slot-type defected ground for reduced cross-polarized radiation. IEEE Antennas and Wireless Propagation Letters, 2014, vol. 14, p. 321-324. DOI: 10.1109/LAWP.2014.2363563

[17] BALANIS, C. A. Antenna Theory: Analysis and Design. $3^{\text {rd }}$ ed. New York: John Wiley \& Sons, 2005. ISBN: 978-0471667827

[18] WHEELER, H. A. The radiation sphere around a small antenna. Proceedings of IRE, 1975, vol. 47, no. 8, p. 1325-1331. DOI: 10.1109/JRPROC.1959.287198

\section{About the Authors ...}

Juin ACHARJEE received her B.Tech. degree and M.Tech. degree in Electronics \& Communication Engineering from the University of Maulana Abul Kalam Azad University of Technology (MAKAUT), in 2010, 2013, respectively. She is currently pursuing her Ph.D. from the National Institute of Technology (NIT Durgapur), West Bengal, India. From 2018 she is working as an Assistant Professor in the St. Thomas College of Engineering \& Technology, Kolkata, India. Her current research interests include the characterization and application of DGS, com- 
pact antenna, UWB antenna and its characterization.

Ram Lakhan KUMAR received his B.Tech. degree in Electronics \& Communication Engineering from NSHM Knowledge Campus Durgapur under the University of Maulana Abul Kalam Azad University of Technology (MAKAUT), in 2017. He is currently associated with Rajdeep Infotech as a system Engineer.

Kaushik MANDAL received his B.Sc. degree in Physics (H), B.Tech. and M.Tech. degree in Radio Physics and Electronics from the University of Calcutta, in 2001, 2004 and 2006, respectively. He received his Ph.D. (Tech.) from the University of Kalyani, in July 2014. From 2016 he is working as an Assistant Professor in the Institute of Radio Physics and Electronics, University of Calcutta, West Bengal, India. He has authored or co-authored of 27 internationally refereed journal papers. His current research interests include the characterization and application of DGS, improvement of radiation properties of antenna, CP antenna design, SIW integrated microstrip antenna, and performance enhancement of microstrip antenna using frequency selective surface (FSS). Dr. Mandal is a co-recipient of the IEEE TENCON 2017 Best Paper Award (in the track 'Antenna'). He is an active reviewer of IEEE Transactions on Antennas and Propagation, IEEE Antennas and Propagation Magazine, IET Microwaves Antennas \& Propagation, Microwave and Optical Technology Letters, Progress In Electromagnetics Research (PIER), and AEÜ International Journal of Electronics and Communications. Dr. Mandal is a senior member of IEEE.

Sujit Kumar MANDAL received B.Sc. degree in Physics (H) from the University of Calcutta in 2001. He completed B.Tech. and M.Tech. in Radio Physics \& Electronics from the Institute of Radio Physics \& Electronics, C. U. in the year 2004 and 2006, respectively. He received Ph.D. degree in the year 2014 from the National Institute of Technology, Durgapur where he is presently an Assistant Professor in the Department of Electronics and Communication Engineering from 2010. He has published more than 35 research papers in national and international peer reviewed journals and conferences. His present research area includes application of soft computing techniques in antenna array optimization, time-modulated antenna arrays, microstrip patch antenna, RF energy harvesting and onchip antenna design. 